\title{
PENINGKATAN HASIL BELAJAR AGAMA BUDDHA DENGAN MENGGUNAKAN MEDIA PEMBELAJARAN YOUTUBE
}

\author{
Sutopo \\ SMA Negeri 1 Bengkalis, Bengkalis, Indonesia \\ sutopo32@guru.sma.belajar.id
}

\begin{abstract}
ABSTRAK
Perkembangan teknologi yang berjalan begitu pesat maka segala kebutuhan manusia disegala bidang akan mengalami sebuah perubahan drastis dari keterlambatan menuju percepatan, dari keterbelakangan menuju kemajuan, dari sifat tertutup menjadi sifat terbuka. Media pembelajaran merupakan salah satu elemen penting dalam proses pembelajaran. Salah satu bentuk media pembelajaran yang digunakan dalam perkembangan teknologi adalah Youtube. Penelitian yang digunakan adalah Penelitian Tindakan Kelas (PTK) dengan menggunakan desain penelitian model Kemmis dan Mc. Taggart yaitu berbentuk spiral dari siklus yang satu ke siklus yang berikutnya. Setiap siklus meliputi planning (rencana), action (tindakan), observation (pengamatan), dan reflection (refleksi). Penelitian ini dilaksanakan di SMA Negeri 1 Bengkalis. Subjek penelitian ini adalah siswa beragama buddha pada kelas X (Sepuluh) IPS SMA Negeri 1 Bengkalis, jumlah siswa sebanyak 24 siswa. Dua siklus yang memperlihatkan hasil belajar peserta didik dengan rata-rata yang meningkat. Siklus I rata-rata yang diperoleh $<75$ (75\%), sedangkan pada siklus II rata-rata yang diperoleh $>75$ (75\%). Penerapan media pembelajaran menggunakan youtube dapat meningkatkan daya tarik siswa terhadap pembelajaran dan dapat meningkatkan hasil belajar siswa.
\end{abstract}

Kata Kunci: teknologi, agama buddha, youtube

\section{INCREASING BUDDHIST LEARNING OUTCOMES USING BY UTILIZING YOUTUBE}

\section{ABSTRACT}

Technology develops so rapidly that all human needs in all fields experience a drastic change from delay to acceleration, from backwardness to progress, and from closed nature to open nature. Learning media is one of the important elements in the learning process. One form of learning media used in technological development is Youtube. This research was Classroom Action Research (CAR). The design in this research was a model of Kemmis and Mc. Taggart in form of a spiral from one cycle to the next cycle. Each cycle included planning, action, observation, and reflection. This research was conducted at SMA Negeri 1 Bengkalis. The subjects of this study were Buddhist students at grade X(Ten) Social Studies of SMA Negeri 1 Bengkalis, for as many as 24 students. Learning in two cycles showed an increase in students' learning outcomes. In the first cycle, the average score was <75 (75\%), while in the second cycle, the average score was $>75$ (75\%). Thus, utilizing youtube increased students' attractiveness to learning and improved students' learning outcomes.

Keywords: technology, buddhist, youtube

\begin{tabular}{|c|c|c|}
\hline Submitted & Accepted & Published \\
\hline 14 September 2021 & 11 November 2021 & 27 November 2021 \\
\hline
\end{tabular}

\begin{tabular}{|l|c|l|}
\hline Citation & $:$ & Sutopo. (2021). Peningkatan Hasil Belajar Agama Buddha Dengan Menggunakan Media Pembelajaran Youtube. Jurnal
\end{tabular} PAJAR (Pendidikan dan Pengajaran), 5(6), 1767-1772. DOI : http://dx.doi.org/10.33578/pjr.v5i6.8583.

\section{PENDAHULUAN}

Dengan adanya perkembangan teknologi yang berjalan begitu pesat maka segala kebutuhan manusia disegala bidang akan mengalami sebuah perubahan drastis dari keterlambatan menuju percepatan, dari keterbelakangan menuju kemajuan, dari sifat tertutup menjadi sifat terbuka, semua itu tidak dapat dihindari oleh siapa pun namun harus diikuti dengan sebijak mungkin. Berbagai macam teknologi dan komunikasi bermunculan dengan tanpa bisa dicegah, akibat dari semakin majunya pola pikir dan keilmuan serta keahlian manusia dalam menghasilkan sebuah alat dan aplikasi dari yang tradisional sampai yang paling modern. Perkembangan teknologi juga berpengaruh pada semua aspek, termasuk dalam aspek pendidikan (Sulistianingsih \& Mukminan, 2019). Begitu juga bidang pendidikan tak lepas dari kemajuan teknologi informasi. Kemajuan dalam bidang pendidikan dapat ditemui seperti artificial intelgent sehingga memudahkan dalam pelaksanaan sesuatu secara procedural (Walyono, 2020). 
Usaha meningkatkan mutu pendidikan di Indonesia yang paling dominan adalah melalui proses belajar mengajar. Menurut Sardiman (2007) proses belajar mengajar pada hakikatnya adalah proses komunikasi. Maka hal ini harus dilengkapi dengan media pembelajaran. Media pembelajaran merupakan salah satu elemen penting dalam proses pembelajaran (Putri \& Muzakki, 2019). Salah satu bentuk media pembelajaran yang digunakan dalam perkembangan teknologi adalah youtube. Youtube merupakan media sosial atau situs web berbagi video yang sebagian besar manusia di dunia mengenal dan menggunakan media ini. Berbagai situs dan program serta konten video ditampilkan oleh youtube guna memberikan hiburan serta pengetahuan bagi para penonton yang menyaksikan atau membuka youtube. Situs, program dan konten video dengan berbagai kategori mulai dari hiburan, diary, ilmu pengetahuan Alam (sains), ilmu pengetahuan sosial, keagamaan serta hal lainnya dapat diakses oleh masyarakat baik secara berbayar maupun gratis (tanpa biaya) (Bintoro, 2014).

Pelaksanaan youtube sebagai media pembelajaran juga digunakan untuk sarana pendidikan Agama Buddha, dalam pandangan Agama Buddha yang bersifat pragmatis tentang teknologi

media sosial yang semakin berkembang peranan youtube sangat penting terutama dalam membantu penyebaran Agama Buddha salah satunya adalah dilingkungan sekolah melalui pelajaran pendidikan Agama Buddha dengan cara memanfaatkan youtube sebagai media pembelajaran dalam mata pelajaran pendidikan Agama Buddha sekarang ini. Hal ini sejalan dengan penelitian Phenjaya (2018) yang mengatakan bahwa pembelajaran pendidikan Agama Buddha membutuhkan model pembelajaran yang menarik bagi siswanya agar peserta didik tidak mudah mengalami kejenuhan dalam kegiatan pembelajaran.

Mempelajari pendidikan agama Buddha membutuhkan kompetensi dalam mengamati dan menguasai fakta, konsep atau prosedur. Hal ini membutuhkan suatu langkah-langkah yang terorganisasi untuk menyajikan materi dalam pembelajaran pendidikan agama Buddha agar peserta didik dapat lebih memahami dan dapat meningkatkan keimanannya, dikarenakan pendidikan Agama Buddha mampu mengembangkan kemampuan peserta didik untuk memperteguh keimanan dan ketakwaan kepada Tuhan Yang Maha Esa dan berakhlak mulia, serta peningkatan potensi spiritual sesuai dengan ajaran agama Buddha melalui media pembelajaran youtube.

\section{METODE PENELITIAN}

Penelitian yang digunakan adalah Penelitian Tindakan Kelas (PTK) dengan menggunakan desain penelitian model Kemmis dan Mc. Taggart yaitu berbentuk spiral dari siklus yang satu ke siklus yang berikutnya. Setiap siklus meliputi planning (rencana), action (tindakan), observation (pengamatan), dan reflection (refleksi).

Secara keseluruhan, empat tahap tersebut digambarkan dalam bentuk spiral. Untuk mengatasi suatu masalah, diperlukan lebih dari satu siklus. Siklus-siklus tersebut saling terkait dan berkelanjutan. Siklus kedua dilaksanakan bila masih ada hal-hal yang kurang berhasil dalam siklus pertama. Siklus ketiga, dilaksanakan karena siklus kedua belum mengatasi masalah, begitu juga siklus-siklus berikutnya (Arikunto, 2009).

Penelitian ini dilaksanakan di SMA Negeri 1 Bengkalis. Subjek penelitian ini adalah siswa beragama buddha pada kelas X (Sepuluh) IPS SMA Negeri 1 Bengkalis dengan jumlah siswa sebanyak 24 siswa. Objek penelitian adalah peningkatan hasil belajar peserta didik. Teknik pengumpulan data menggunakan observasi dan wawancara. Instrumen yang digunakan tes tertulis individu selama 16 kali pertemuan tentang pelajaran agama Buddha. Data dianalisis secara kuantitatif dan disajikan dalam bentuk tabel.

\section{HASIL DAN PEMBAHASAN}

Pelaksanaan tindakan selama 2 siklus yang dilakukan sebanyak 16 kali pertemuan pada pelajaran Pendidikan Agama Buddha, diperoleh data bahwa hasil belajar siswa mengalami peningkatan. Peningkatan hasil belajar Pendidikan Agama Buddha diketahui dengan menerapkan media pembelajaran Youtube. 


\section{Pelaksanaan Siklus I}

Hal pertama yang peneliti lakukan sebelum melakukan tindakan, peneliti melakukan pelaksanaan pre tindakan dengan menggunakan tes uraian (asessment) yang diberikan kepada siswa berkaitan degan mata pelajaran Pendidikan Agama Buddha. Berdasarkan hasil tes menunjukan hasil belajar siswa yang tes awal. (25\%) dinyatakan tuntas dan sebanyak 6 siswa $(75 \%)$ dinyatakan tidak tuntas sebanyak 18 siswa. Hasil di atas menunjukkan semua siswa memiliki nilai KKM $<75(75 \%)$. Oleh karena itu dengan melihat rendahnya penilaian hasil belajar siswa maka diperlukan suatu langkah pembelajaran untuk dapat meningkatkan hasil belajar siswa.

Setelah ditetapkan untuk menerapkan media pembelajaran youtube, selanjutnya ada beberapa yang perlu dipersiapkan guru membuat perangkat pembelajaran berupa RPP, LKPD, dan Media Pembelajaran yang memuat tindakan yang akan dilakukan dalam penelitian. Sedangkan untuk pelaksanaan dan hasil belajar dapat dilihat pada tabel berikut :

Tabel 1. Hasil Belajar pada Siklus I Pertemuan 1 s.d 8

\begin{tabular}{|c|c|c|c|c|c|c|c|c|c|c|}
\hline No & Nama Inisial & & & & asil & elaj & & & & Rata-rata \\
\hline 1 & $\mathrm{NJ}$ & 75 & 72 & 70 & 65 & 70 & 75 & 78 & 74 & 72.37 \\
\hline 2 & SWI & 76 & 77 & 75 & 70 & 72 & 74 & 78 & 76 & 74.75 \\
\hline 3 & SF & 80 & 75 & 78 & 78 & 75 & 80 & 76 & 79 & 77.62 \\
\hline 4 & IT & 78 & 78 & 75 & 74 & 78 & 79 & 80 & 76 & 77.25 \\
\hline 5 & QF & 65 & 78 & 78 & 77 & 75 & 72 & 70 & 70 & 73.12 \\
\hline 6 & IM & 78 & 80 & 80 & 79 & 74 & 75 & 78 & 75 & 77.37 \\
\hline 7 & GS & 80 & 80 & 75 & 78 & 78 & 74 & 72 & 80 & 77.12 \\
\hline 8 & IR & 75 & 75 & 65 & 72 & 70 & 78 & 78 & 75 & 73.5 \\
\hline 9 & MA & 75 & 75 & 70 & 70 & 70 & 65 & 78 & 70 & 71.62 \\
\hline 10 & LA & 80 & 80 & 78 & 78 & 78 & 75 & 78 & 78 & 78.12 \\
\hline 11 & DD & 80 & 78 & 78 & 76 & 75 & 75 & 80 & 80 & 77.75 \\
\hline 12 & RY & 75 & 65 & 65 & 75 & 70 & 70 & 72 & 70 & 70.25 \\
\hline 13 & HG & 75 & 70 & 70 & 72 & 76 & 78 & 70 & 70 & 72.62 \\
\hline 14 & $\mathrm{AF}$ & 75 & 78 & 79 & 76 & 74 & 70 & 70 & 70 & 74 \\
\hline 15 & NBY & 76 & 75 & 72 & 78 & 78 & 70 & 70 & 65 & 73 \\
\hline 16 & YSH & 70 & 70 & 65 & 65 & 70 & 65 & 70 & 72 & 68.37 \\
\hline 17 & TE & 75 & 78 & 70 & 70 & 65 & 70 & 78 & 70 & 72 \\
\hline 18 & CGM & 75 & 75 & 70 & 65 & 78 & 70 & 65 & 78 & 72 \\
\hline 19 & $\mathrm{HJ}$ & 75 & 65 & 70 & 65 & 70 & 70 & 65 & 78 & 69.75 \\
\hline 20 & KLO & 70 & 65 & 70 & 70 & 68 & 70 & 68 & 75 & 69.5 \\
\hline 21 & MPI & 70 & 70 & 65 & 70 & 75 & 65 & 70 & 78 & 70.37 \\
\hline 22 & MXF & 78 & 70 & 65 & 75 & 70 & 68 & 70 & 72 & 71 \\
\hline 23 & CLLM & 75 & 78 & 78 & 75 & 65 & 72 & 70 & 72 & 73.12 \\
\hline 24 & QSD & 70 & 70 & 72 & 70 & 75 & 70 & 68 & 70 & 70.62 \\
\hline
\end{tabular}




\section{Pelaksanaan Siklus II}

Pada kegiatan siklus II dari pertemuan sembilan sampai pertemuan enam belas aktivitas siswa dalam kegiatan pembelajaran dan hasil belajar siswa menunjukan peningkatan yang signifikan dan mengalami peningkatan jika dibandingkan dengan siklus I. Berdasarkan hasil tes menunjukan hasil belajar siswa (75\%) dinyatakan tuntas sebanyak 18 siswa $(25 \%)$ dinyatakan tidak tuntas sebanyak 6 siswa. Hasil di atas menunjukkan semua siswa memiliki nilai $\mathrm{KKM}>75(75 \%)$

Hal ini didukung dengan media pembelajaran yaitu youtube, dengan adanya media pembelajaran ini siswa lebih fokus dan lebih memperhatikan ketika diberikan materi oleh guru. Guru juga mempersiapkan perangkat pembelajaran berupa RPP, LKPD, dan Media Pembelajaran yang memuat tindakan yang akan dilakukan dalam penelitian. Sedangkan untuk pelaksanaan dan hasil belajar dapat dilihat pada tabel berikut :

Tabel 2. Hasil Belajar pada Siklus II Pertemuan 9 s.d 16

\begin{tabular}{ccccccccccc}
\hline No & Nama Inisial & \multicolumn{6}{c}{ Hasil Belajar } & Rata-rata \\
\hline $\mathbf{1}$ & NJ & 72 & 72 & 70 & 78 & 78 & 75 & 78 & 74 & 74.62 \\
$\mathbf{2}$ & SWI & 75 & 77 & 75 & 70 & 72 & 74 & 78 & 76 & 74.62 \\
$\mathbf{3}$ & SF & 85 & 75 & 78 & 78 & 75 & 80 & 76 & 79 & $\mathbf{7 8 . 2 5}$ \\
$\mathbf{4}$ & IT & 80 & 78 & 75 & 74 & 78 & 79 & 80 & 76 & $\mathbf{7 7 . 5}$ \\
$\mathbf{5}$ & QF & 75 & 75 & 74 & 77 & 75 & 72 & 75 & 76 & 74.87 \\
$\mathbf{6}$ & IM & 80 & 80 & 80 & 79 & 74 & 75 & 78 & 75 & $\mathbf{7 7 . 6 2}$ \\
$\mathbf{7}$ & GS & 80 & 80 & 75 & 78 & 78 & 74 & 72 & 80 & $\mathbf{7 7 . 1 2}$ \\
$\mathbf{8}$ & IR & 78 & 75 & 70 & 72 & 70 & 78 & 78 & 75 & 74.5 \\
$\mathbf{9}$ & MA & 75 & 75 & 75 & 70 & 70 & 78 & 78 & 70 & 73.87 \\
$\mathbf{1 0}$ & LA & 80 & 80 & 78 & 82 & 78 & 75 & 78 & 80 & $\mathbf{7 8 . 8 7}$ \\
$\mathbf{1 1}$ & DD & 80 & 78 & 82 & 78 & 78 & 82 & 82 & 80 & $\mathbf{8 0}$ \\
$\mathbf{1 2}$ & RY & 78 & 75 & 80 & 78 & 78 & 78 & 75 & 70 & $\mathbf{7 6 . 5}$ \\
$\mathbf{1 3}$ & HG & 78 & 78 & 80 & 75 & 80 & 78 & 82 & 70 & $\mathbf{7 7 . 6 2}$ \\
$\mathbf{1 4}$ & AF & 76 & 80 & 82 & 76 & 74 & 75 & 78 & 72 & $\mathbf{7 6 . 6 2}$ \\
$\mathbf{1 5}$ & NBY & 78 & 78 & 78 & 78 & 75 & 75 & 75 & 70 & $\mathbf{7 5 . 8 7}$ \\
$\mathbf{1 6}$ & YSH & 78 & 75 & 78 & 78 & 80 & 70 & 75 & 72 & $\mathbf{7 5 . 7 5}$ \\
$\mathbf{1 7}$ & TE & 80 & 78 & 75 & 75 & 80 & 78 & 78 & 75 & $\mathbf{7 7 . 3 7}$ \\
$\mathbf{1 8}$ & CGM & 78 & 78 & 75 & 78 & 78 & 78 & 75 & 78 & $\mathbf{7 7 . 2 5}$ \\
$\mathbf{1 9}$ & HJ & 80 & 80 & 78 & 76 & 76 & 78 & 75 & 78 & $\mathbf{7 7 . 6 2}$ \\
$\mathbf{2 0}$ & KLO & 82 & 78 & 75 & 72 & 78 & 80 & 70 & 75 & $\mathbf{7 6 . 2 5}$ \\
$\mathbf{2 1}$ & MPI & 78 & 76 & 74 & 76 & 78 & 75 & 70 & 78 & $\mathbf{7 5 . 6 2}$ \\
$\mathbf{2 2}$ & MXF & 82 & 75 & 78 & 78 & 75 & 80 & 70 & 75 & $\mathbf{7 6 . 6 2}$ \\
$\mathbf{2 3}$ & CLLM & 80 & 78 & 80 & 75 & 75 & 78 & 70 & 75 & $\mathbf{7 6 . 3 7}$ \\
$\mathbf{2 4}$ & QSD & 78 & 75 & 75 & 70 & 75 & 72 & 75 & 78 & 74.75 \\
\hline & & & & & & & & & \\
& & 75 &
\end{tabular}


Pada penelitian ini dilaksanakan tindakan pada masing-masing siklusnya yaitu, pada setiap siklusnya didapatkan data mengenai perencanaan pembelajaran, pelaksanaan pembelajaran, hasil belajar siswa dan respon siswa terhadap pembelajaran setelah diberikan media pembelajaran. Berdasarkan pengamatan pada siklus I pada pertemuan 1-8 terlihat bahwa guru melakukan perencanaan dengan membuat perangkat pembelajaran meliput RPP, LKPD, dan Media Pembelajaran. Dari tabel 1 diatas dapat dijelaskan jumlah nilai rata-rata yang dilakukan penelitian belum mencapai KKM, untuk KKM pendidikan agama Buddha adalah 75. Diperoleh yang tuntas hanya 6 siswa, sedangkan yang lainnya masuk dalam kategori tidak tuntas sebanyak 18 siswa.

Adapun aktivitas guru yang tidak dilakukan adalah penyajian materi tanpa menggunakan media pembelajaran yang menarik. Karena media pembelajaran yang dirancang secara baik akan sangat membantu peserta didik dalam mencerna dan memahami materi pelajaran (Musyadat, 2017). Media pembelajaran juga akan membantu keefektifan proses pembelajaran dalam penyampaian pesan dan isi pelajaran (Fitria, 2018).

Sedangkan pada siklus II dilakukan pada pertemuan 9-16, dalam hal ini selain guru melakukan perencanaan dengan membuat perangkat pembelajaran meliput RPP, LKPD, guru juga menyajikan media pembelajaran yang lebih menarik yaitu dengan menggunakan media pembelajaran youtube dengan menampilkan banyak hal-hal yang menarik untuk dipahami dan diperhatikan oleh peserta didik mengenai Pendidikan Agama Buddha.

Diperoleh berdasarkan hasil tes menunjukan hasil belajar siswa $(75 \%)$ dinyatakan tuntas sebanyak 18 siswa, $(25 \%)$ dinyatakan tidak tuntas sebanyak 6 siswa. Hasil di atas menunjukkan semua siswa memiliki nilai KMM $>75(75 \%)$. Ini menunjukkan bahwa penelitian tindakan kelas dengan menggunakan media pembelajaran youtube dengan menyajikan videovideo atau konten-konten yang menarik sangat berpengaruh terhadap hasil belajar siswa. Sejalan penelitian Daryanto yang mengatakan bahwa media video merupakan suatu medium yang sangat efektif untuk membantu proses pembelajaran baik untuk pembelajaran masal, individu, maupun berkelompok. (Daryanto, 2016).

Meningkatnya daya tarik siswa dan hasil belajar siswa ini tidak lepas dari peran media pembelajaran youtube, dimana media pembelajaran youtube merupakan media yang sangat efektif untuk pembelajaran individual maupun kelompok. Tidak hanya itu media pembelajaran youtube memiliki kelebihan dapat diputar kembali sesuai kebutuhan, dan memiliki konten-konten yang menarik seputar mata pelajaran salah satunya yaitu mata pelajaran Pendidikan Agama Buddha.

\section{SIMPULAN DAN REKOMENDASI}

Penerapan media pembelajaran menggunakan youtube berdasarkan hasil penelitian dan pembahasan dapat disimpulkan bahwa dengan media pembelajaran youtube dapat meningkatkan daya tarik siswa terhadap pembelajaran dan dapat meningkatkan hasil belajar siswa. Hasil belajar yang sebelumnya ratarata $<75(75 \%)$ menjadi $>75(75 \%)$, respon siswa terhadap media yang digunakan menarik dan dapat meningkatkan pemahaman mereka tentang materi pembelajaran.

Saran untuk guru mata pelajaran lebih memberikan pembelajaran yang menarik dalam pembelajaran, agar peserta didik lebih tertarik dan memahami pada proses pembelajaran yang dilaksanakan.

\section{DAFTAR PUSTAKA}

Arikunto, S. (2009). Prosedur Penelitian Suatu Pendekatan Praktik. Jakarta: Rineka Cipta Bintoro, I. (2021). Menjadikan Youtube Sebagai Media Pembelajaran Baru. dalam http://menjadikan-youtube-sebagaimedia-pembelajaran-baru/, retrieved. Org $10-10-2021$

Daryanto. (2016). Media Pembelajaran. Yogyakarta: Gava Media.

Fitria, A. (2018). Penggunaan Media Audio Visual Dalam Pembelajaran Anak Usia Dini. Cakrawala Dini: Jurnal Pendidikan Anak 
Jurnal PAJAR (Pendidikan dan Pengajaran)

Volume 5 Nomor 6 November | ISSN Cetak : 2580 - 8435| | ISSN Online : 2614 - 1337

DOI : http://dx.doi.org/10.33578/pjr.v5i6.8583

Usia Dini. 5(2).

https://doi.org/10.17509/cd.v5i2.10498.

Musyadat, I. (2017). Pengembangan Media Pembelajaran Berbasis Video. Jurnal Dimensi Pendidikan Dan Pembelajaran.

Phenjaya, Erica Winata. (2018). Upaya Peningkatan Hasil Belajar Pendidikan Agama Buddha Menggunakan Model Pembelajaran Kooperatif Tipe Think Pair Share Siswa Middle Years Programme Di Medan Independent School. Jurnal Prointegrita. 2 (348/XII/Pasca-UDA). 100-108

Putri, A. R., \& Muzakki, M. A. (2019). Implemetasi Kahoot sebagai Media Pembelajaran Berbasis Digital Game Based Learning dalam Mengahadapi Era Revolusi Industri 4.0. Prosiding Seminar Nasional Universitas Muria Kudus.

Sardiman. A. M. (2007). Interaksi dan Motivasi Belajar. Jakarta: CV Rajawali

Sulistianingsih, E., \& Mukminan, M. (2019). The Development Of Web-Based Learning Multimedia For High School Students' Lithosphere Material. Geosfera Indonesia. https://doi.org/10.19184/geosi.v4i1.9882.

Walyono. (2020). Penerapan Media Video untuk Meningkatkan Pemahaman Mahasiswa Prodi Kependidikan Agama Buddha STABN Raden Wijaya. ABIP Jurnal Agama Buddha dan Ilmu pengetahuan. 6(1). $84-88$ 